\title{
XENOGRAFT TRANSPLANTATION OF HUMAN MALIGNANT ASTROCYTOMA CELLS INTO IMMUNODEFICIENT RATS: AN EXPERIMENTAL MODEL OF GLIOBLASTOMA
}

\author{
Flávio Key Miura, Maria Jose Ferreira Alves, Mussya Cisotto Rocha, Roseli da \\ Silva, Sueli Mieko Oba-Shinjo, Suely Kazue Nagahashi Marie
}

doi: $10.1590 / \mathbf{S 1 8 0 7 - 5 9 3 2 2 0 1 0 0 0 0 3 0 0 0 1 1}$

\begin{abstract}
Miura FK, Alves MJF, Rocha MC, Silva R, Oba-Shinjo SM, Marie SKN. Xenograft transplantation of human malignant astrocytoma cells into immunodeficient rats: an experimental model of glioblastoma. 2010;65(3):305-9.
\end{abstract}

INTRODUCTION: Astrocytic gliomas are the most common intracranial central nervous system neoplasias, accounting for about $60 \%$ of all primary central nervous system tumors. Despite advances in the treatment of gliomas, no effective therapeutic approach is yet available; hence, the search for a more realistic model to generate more effective therapies is essential.

OBJECTIVE: To develop an experimental malignant astrocytoma model with the characteristics of the human tumor.

METHOD: Primary cells from subcutaneous xenograft tumors produced with malignant astrocytoma U87MG cells were inoculated intracerebrally by stereotaxis into immunosuppressed (athymic) Rowett rats.

RESULTS: All four injected animals developed non-infiltrative tumors, although other glioblastoma characteristics, such as necrosis, pseudopalisading cells and intense mitotic activity, were observed.

CONCLUSION: A malignant astrocytoma intracerebral xenograft model with poorly invasive behavior was achieved in athymic Rowett rats. Tumor invasiveness in an experimental animal model may depend on a combination of several factors, including the cell line used to induce tumor formation, the rat strains and the status of the animal's immune system.

KEYWORDS: Brain tumor; Experimental model; Athymic Rowett rats; U87MG cells.

\section{INTRODUCTION}

Astrocytic gliomas are the most common intracranial neoplasias, and diffusely infiltrating astrocytomas, specifically WHO grade II to IV astrocytomas, account for about $60 \%$ of all primary central nervous system tumors. ${ }^{1}$ Despite the advances in the treatment of gliomas, no effective therapeutic approach is available, and the prognosis of glioma patients remains poor and is less than 12 months of survival after diagnosis of grade IV glioblastoma (GBM). ${ }^{2}$ New treatments can only be tested if realistic models are available. Therefore, the search for experimental in vitro and

Laboratory of Molecular and Cellular Biology, LIM 15, Faculdade de Medicina da Universidade de São Paulo - São Paulo/SP, Brazil.

Email: fkmiura@hotmail.com

Tel.: 55113069.7152

Received for publication on November 30, 2009

Accepted for publication on December 14, 2009 in vivo models that better mimic the primary characteristics of these tumors is essential.

There are few currently available animal brain tumor models that exactly simulates the characteristics of human malignant gliomas, which include the invasive growth, neovascularization, necrosis and pseudopalisading cells. ${ }^{3-5}$ Despite this limitation, the current animal models have been useful for developing new therapeutic modalities and have provided a wealth of information pertaining to the genetic events in oncogenesis. ${ }^{6-9}$ The current models of rat malignant glioma use concentrated cell suspensions of tissue culturederived brain tumor cells. Most researchers have used the stereotactic approach as the implantation technique. The stereotactic coordinates are aimed at structures deeper in the white matter, usually the caudate nucleus. There are two basic types of cell-host combinations: animals that are immunologically compatible with tumors that were maintained via cell culture for prolonged periods and 
xenograft transplantation in which human tumor cells are implanted into immunodeficient recipient animals. The use of established rat brain tumor cell lines (such as 9L and C6) permits experiments in immunologically compatible rats (such as Wistar and Fischer rats) (allograft). However, such immunologically compatible rat brain tumors usually display low invasiveness of the surrounding brain tissue and do not recapitulate the histopathology of human primary gliomas. ${ }^{3,8,10-13}$

Xenograft models are based on the intracerebral implantation of human brain tumor cells into immunodeficient rats (xenotransplantation). The aim of the present study was to develop a xenograft model of a human brain tumor using a human malignant astrocytoma cell line (U87MG) and athymic rats (Rowett).

\section{MATERIAL AND METHODS}

\section{Cell culture}

The human malignant astrocytoma cell line U87MG was obtained from the American Type Culture Collection. Monolayers of U87MG cells and primary cells from subcutaneous tumors were grown to $70 \%$ confluence in Dulbecco's modified Eagle medium (DMEM) supplemented with $10 \%$ fetal bovine serum, $100 \mathrm{U} / \mathrm{mL}$ of penicillin $\mathrm{G}$ sodium and $100 \mu \mathrm{g} / \mathrm{mL}$ of streptomycin-sulfate in a humidified atmosphere at $37^{\circ} \mathrm{C}$ with $5 \% \mathrm{CO}_{2}$. Confluent dishes were trypsinized with $0.05 \%$ trypsin- $0.002 \%$ ethylenediamine tetraacetic acid (Life Technologies, Inc, NY), and the cells were resuspended in DMEM. Primary cell cultures were obtained by mincing tumors immediately after their removal from the animal.

\section{In vivo xenograft tumor model}

Eight female Rowett rats, 8 weeks old with an average weight of $140 \mathrm{~g}$, were used for the experiments. To establish U87MG xenograft tumors in rats, four rats were injected subcutaneously in the right flank with $1 \times 10^{5}$ cells suspended in $100 \mu \mathrm{L}$ of DMEM. Flank tumors were measured with calipers. Animals were sacrificed when the flank tumor grew to a size of $2.5 \mathrm{~cm}$ (approximately 35 days after inoculation).

Intracranial inoculations were performed in four rats with the primary cell culture obtained from subcutaneous tumors. The rats were anesthetized with intraperitoneal ketamine hydrochloride $(90 \mathrm{mg} / \mathrm{kg}$ ) and placed in a stereotaxic head frame (Kopf, Germany). The frontal right lobe was accessed by trepanation. Antisepsis of the skin covering the cranium was performed using $70 \%$ alcohol, and a median incision of approximately $1 \mathrm{~cm}$ was made. Access to the cranial cavity was achieved by means of a right frontal burr hole, $2 \mathrm{~mm}$ in front of the coronal suture and $2 \mathrm{~mm}$ to the side of the sagittal suture (Figure 1A). This procedure was carried out using an electric mini-drill (Bosch). A total of $1 \times 10^{5}$ cells in $4 \mu \mathrm{L}$ of DMEM was injected $3 \mathrm{~mm}$ deep with a Hamilton syringe. The needle was left in position for 10 minutes and was then withdrawn slowly. The scalp wound was sutured with 5-0 mononylon. The rats were assessed daily, specifically for changes in gait that would suggest a motor deficit and for secretions accumulating in the periocular region; when these conditions were observed, the rats were sacrificed using a thionembutal overdose. Cardiac perfusion was performed with $100 \mathrm{~mL}$ phosphate-buffered saline (PBS) and $80 \mathrm{~mL}$ of paraformaldehyde (4\%), followed by extraction of the brain. Whole brains were fixed in $4 \%$ paraformaldehyde for one week at room temperature, sliced antero-posteriorly in $0.5-\mathrm{cm}$ thick coronal specimens, embedded in paraffin blocks and sectioned at $5 \mu \mathrm{m}$. Representative tumor sections, together with the surrounding cerebral tissue, were mounted on microscope slides and stained with hematoxylin-eosin. The diameter of the largest section of each tumor sample was measured with calipers.

\section{RESULTS}

\section{Subcutaneous inoculation}

All four injected animals developed a clearly palpable tumor after 21 days. Within 35 days of inoculation, all tumors reached $2.5 \pm 0.2 \mathrm{~cm}$ in diameter. Histopathological analysis showed the presence of highly proliferative and well-vascularized masses. Other features of GBM were also identified, including necrotic areas, nuclear pleomorphism, mitotic activity and endothelial hyperplasia.

\section{Intracranial tumor implantation}

The procedure for implanting the U87MG cells was well tolerated. No complication related to the surgical or anesthetic procedure was observed. Twenty days after implantation, signs of periocular secretion build-up were observed. Motor deficit was observed 24 days after inoculation, when the rats were sacrificed. No extra-cerebral masses were observed. All rats developed brain tumors in the form of a single intracerebral mass growing over the cortical surface and centered upon the injection site (Figure 1B).

The diameters of the largest $5 \mu \mathrm{m}$ microscopic tumor slice section were measured for each sample. The lateral-lateral diameter ranged from $0.5 \mathrm{~cm}$ to $0.9 \mathrm{~cm}$ (average $0.7 \mathrm{~cm}$ ), and the cranio-caudal diameter ranged from $0.3 \mathrm{~cm}$ to 0.6 

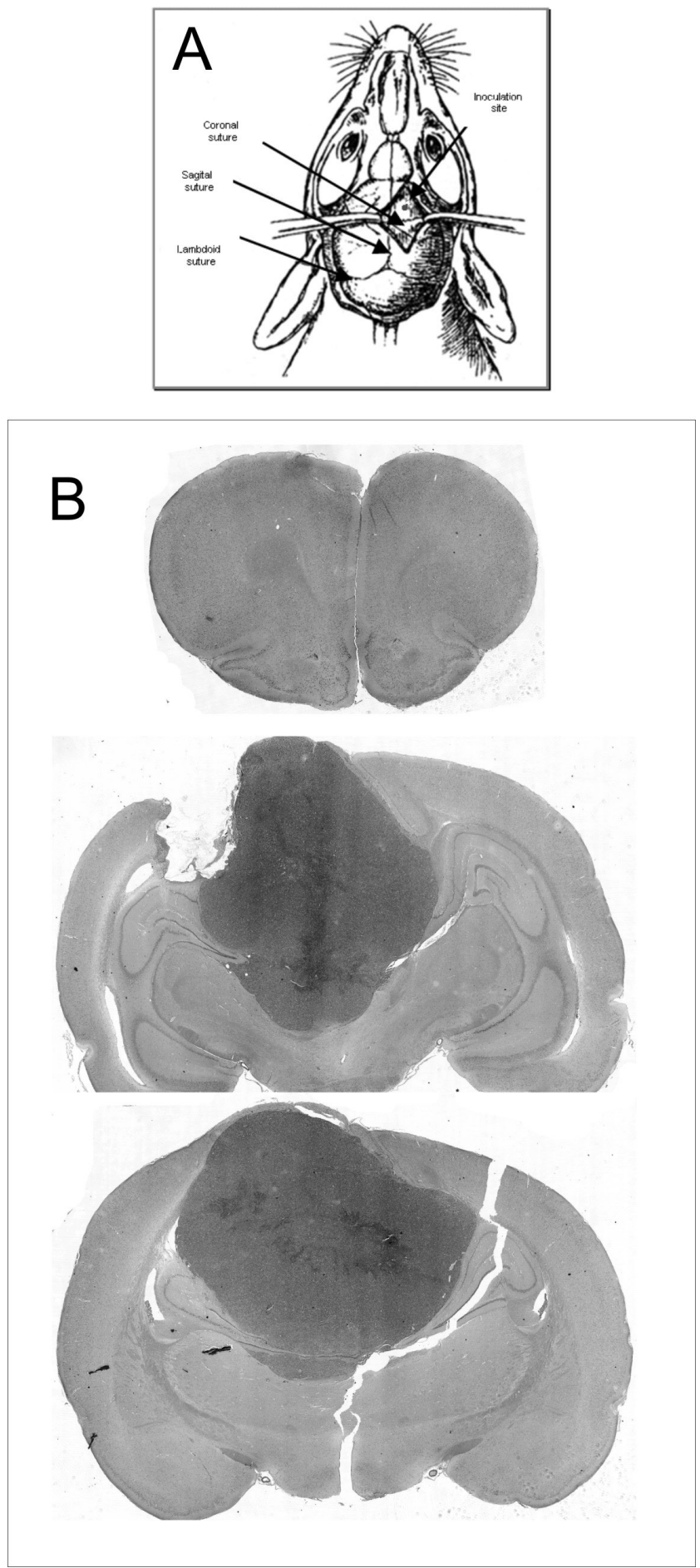

Figure 1 - A: Schematic of a rat skull showing the inoculation site with respect to the sutures (modified from Lal S et al. ${ }^{18}$ ). B: Scanned slide of a coronal section shows a single tumor mass centered at the inoculation site.

$\mathrm{cm}$ (average $0.5 \mathrm{~cm}$ ).

Microscope analysis of the brain tumors showed the presence of neoplastic characteristics resembling human GBM, such as neovascularization, hemorrhagic necrotic clusters, pseudopalisading cells and mitotic activity (Figure 2). The brain-tumor interface was clearly seen and did not show microscopic infiltration at the borders of the primary lesion. Groups of tumor cells were not found beyond the edges of the main mass. Tumor cells did not infiltrate either the leptomeningeal or the perivascular spaces. There was little inflammatory response adjacent to the tumor lesion.

\section{DISCUSSION}

Solid malignant tumors are curable when an early diagnosis is made and the tumor is radically removed. Successful treatment of GBM is still a challenge because the tumor is of a considerable size when it is first diagnosed, and radical resection is impossible because of its infiltrative nature. The degree of tumor invasiveness depends on the characteristics of the neoplastic cells and also on immunological tumor-host interactions.

Regarding experimental brain tumors, the immunological interaction is fundamental to the development of tumor masses because the current models are based on tumor cell implantation in rats and mice. Basically, two methodologies are employed: 1) immunologically compatible tumor cells are injected into a receptor animal (allograft) or 2) non-immunologically compatible tumor cells are injected into immune-deficient animals (xenografts). In the latter case, animals can be congenitally immunosuppressed (athymic animals, like Rowett rats and nude mice) or can be immunosuppressed using anti-rejection drugs, like cyclosporin.

In a previous study, we tested a third combination, using immunologically compatible cells (C6 cell line) in immunocompromised rats (Rowett rat). This combination resulted in brain tumors with infiltrative characteristics very similar to human $\mathrm{GBM},{ }^{14}$ with a higher degree of infiltration than that observed in the immunologically compatible model using the C6 cell line in immunocompetent Wistar rats. ${ }^{12}$ Similar results have been reported with New Zealand athymic rats. ${ }^{4}$ These data suggest that the absence of an immunological response, or more precisely a weak immunological response, contributes to the invasiveness of a brain tumor. Nevertheless, we expected that the present xenograft model, which used a human malignant astrocytoma cell line (U87MG) in athymic rats (Rowett), could generate an infiltrative tumor. However, we observed a well-circumscribed tumor with low infiltration of the adjacent brain parenchyma under optic microscope analysis.

Guillamo et al. ${ }^{5}$ also used this third combination (GL15 GBM cells implanted in immunosuppressed animals), and they observed a very infiltrative lesion that reached the normal brain parenchyma surrounding the tumor as well as normal grey and white matter.

Some possible explanations for this apparent discrepancy 

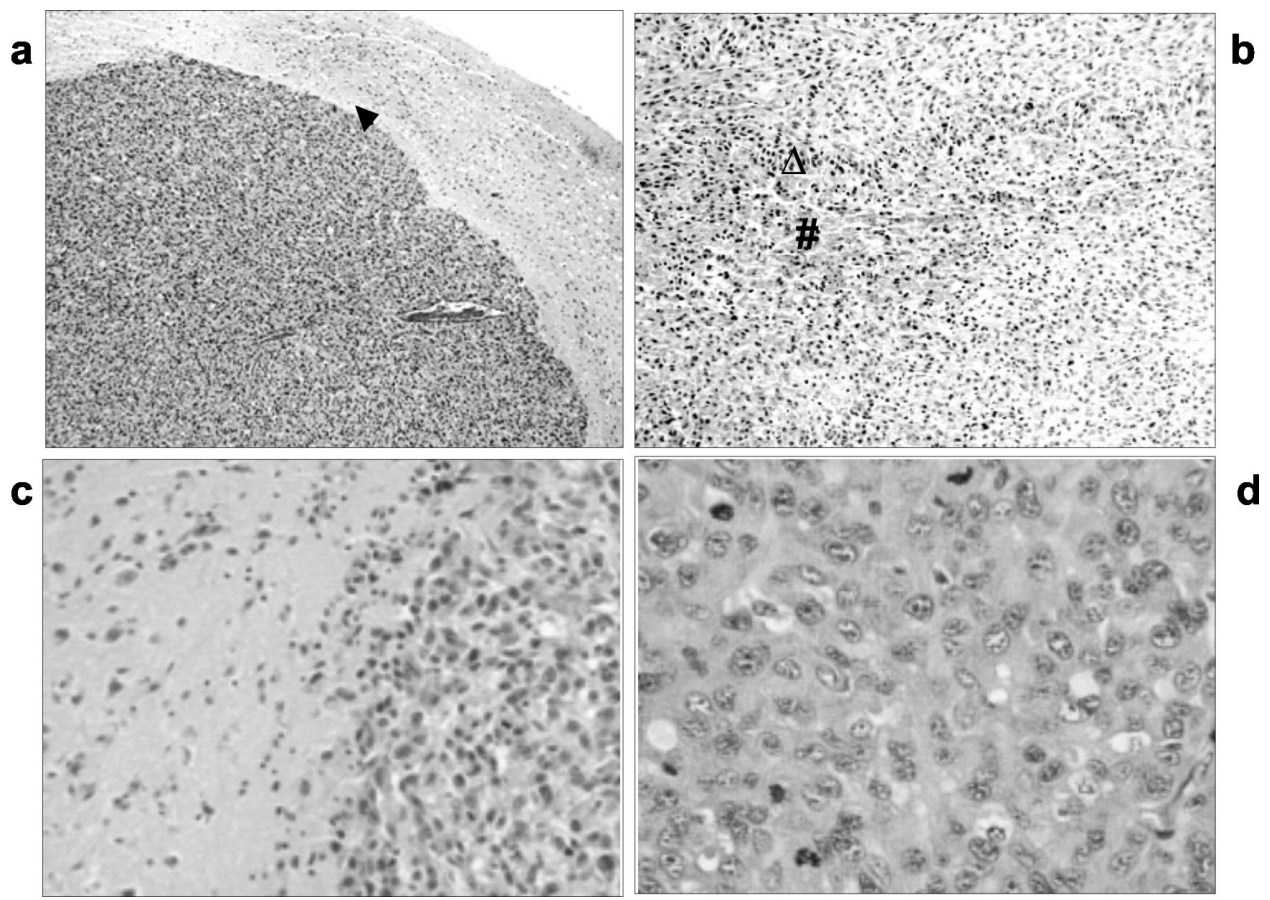

Figure 2 - H\&E. Intra-cerebral tumor induced by inoculation of U87MG cells in Provett rats. (a) Brain-tumor interface (A) with high cellularity and neovascularization, 40x; (b) palisading $(\triangle$ ) cells surrounding a necrotic area (\#), 100x; (c) brain tissue (left) and tumoral tissue (right), 200x; (d) mitotic activity, 400x.

are that immunological interactions have little influence in tumor circumscription in experimental animal models or that invasiveness to distant places depends on other interactions that are more dependent on the combination of the cell type and the rat/mouse strain.

C6-induced tumors are strongly influenced by the rat strain used for inoculation. Tumors developed in SpragueDawley and Long-Evans animals are encapsulated, delimited and well delineated, resembling metastatic lesions ${ }^{15}$. When inoculated into Wistar rat brains, tumors have invasive characteristics similar to those of GBM, including necrosis and hemorrhage. ${ }^{4}$

The importance of this immunological combination in invasiveness has been investigated by $\mathrm{C} 6$ cells simultaneous inoculations in subcutaneous and intracerebral sites in Wistar rats, and no tumor development was observed. An anti-tumoral immune response induced by subcutaneous inoculated cells that thwarted tumor growth in the brain is a plausible explanation for such a result. ${ }^{12}$ Similarly, Mourad et al. performed combinations of implant experiments (brain and/or systemic inoculation) with compatible and non-compatible cells, and they concluded that GBM cells are antigenic but not immunogenic for their compatible host. ${ }^{16}$
It is also necessary to emphasize that there is an immunological response even in correct immunological associations (immunologically compatible graft-host or graft-immunosuppressed host). This immunological response can be inferred by the presence of a peritumoral immunological response and by the spontaneous disappearance of experimental brain tumors over time. ${ }^{17}$

It is also possible that strain differences in the cellcell interaction or cell-stromal relationships that exist between rodents and humans are sufficiently important that the invasive characteristics of human xenografts are not maintained in these experimental grafts.

In conclusion, we obtained brain tumors with limited invasive characteristics in our experimental model using U87MG cells implanted in athymic Rowett rats. We speculate that the infiltrative or non-infiltrative characteristic of a tumor in an experimental animal model depends on the combination of the cell line and the rat strain in addition to the presence of an active immune system.

\section{ACKNOWLEDGMENTS}

This project was supported by FAPESP (04/12133-6) and the Ludwig Institute for Cancer Research, New York, USA. 


\section{REFERENCES}

1. Louis DN, Ohgaki H, Wiestler OD, Cavenee WK, Burger PC, Jouvet A, et al. The 2007 classification of tumors of the central nervous system. Acta Neuropathol. 2007;114:97-109.

2. Clara CA, Almeida JRW, Miura F, Malheiros SMF, Carlotti CG, Bianco A, et al. Glioblastoma: survival analysis and prognostic factors among 434 cases. Arq Neuropsiquiatr. 2010 [in press].

3. Barth RF. Rat brain tumor models in experimental neuro-oncology: the 91, c6, t9, f98, rg2 (d74), rt-2 and CNS-1 gliomas. J Neurooncol. 1998;36:91-102.

4. Saini M, Bellinzona M, Meyer F, Cali G, Samii M. Morphometrical characterization of two glioma models in the brain of immunocompetent and immunodeficient rats. J Neurooncol. 1999;42:59-67.

5. Guillamo JS, Lisovoski F, Christov C, Le Guerinel C, Defer Gl, Peschanski M, et al. Migration pathways of human glioblastoma cells xenografted into the immunosuppressed rat brain. J Neurooncol. 2001;52:205-15.

6. Fomchenko EI, Holland EC. Mouse models of brain tumors and their applications in preclinical trials. Clin Cancer Res. 2006;12:5288-97.

7. Maher EA, Furnari FB, Bachoo RM, Rowitch DH, Louis DN, Cavenee WK, et al. Malignant glioma: genetics and biology of a grave matter. Genes Dev. 2001;15:1311-33.

8. Peterson DL, Sheridan PJ, Brown WE Jr. Animal models for brain tumors: historical perspectives and future directions. J Neurosurg. 1994;80:865-76.

9. Strojnik T, Kavalar R, Lah TT. Experimental model and immunohistochemical analyses of U87 human glioblastoma cell xenografts in imunosuppressed rat brains. Anticancer Res. 2006; 26:2887-900.

10. Grobben B, De Deyn PP, Slegers H. Rat C6 glioma as experimental model system for the study of glioblastoma growth and invasion. Cell Tissue Res. 2002;310:257-70.
11. Michailowsky C, Miura FK, do Valle AC, Sonohara S, Meneguin TD, Tsanaclis AM. Experimental tumors of the central nervous system: standardisation of a model in rats using the 9L glioma cells. Arq Neuropsiquiatr. 2003;61(2A):234-40.

12. Parsa AT, Chakrabarti I, Hurley PT, Chi JH, Hall JS, Kaiser MG, et al. Limitations of the C6/Wistar rat intracerebral glioma model: implications for evaluating immunotherapy. Neurosurgery. 2000;47:993-9.

13. Weizsaecker M, Deen DF, Rosenblum ML, Hoshino T, Gutin PH, Barker M. The 9L rat brain tumor: description and application of an animal model. J Neurol. 1981;224:183-92.

14. Miura FK, Alves MJ, Rocha MC, Silva RS, Oba-Shinjo SM, Uno M, et al. Experimental nodel of C6 brain tumors in athymic rats. Arq Neuropsiquiatr. 2008;66:238-41.

15. Mokrý J, Nĕmecek S, Adler J, Dĕdic K Inoculation of C6 cell suspension into the brain of adult rats: immunohistochemical study. Funct Dev Morphol. 1993;3:175-80.

16. Mourad PD, Farrell L, Stamps LD, Chicoine MR, Silbergeld D1. Why are systemic glioblastoma metastases rare? Systemic and cerebral growth of mouse glioblastoma. Surg Neurol. 2005;63:511-9.

17. Vince GH, Bendszus M, Schweitzer T, Goldbrunner RH, Hildebrandt $\mathrm{S}$, Tilgner J, et al. Spontaneous regression of experimental gliomasan immunohistochemical and MRI study of the C6 glioma spheroid implantation model. Exp Neurol. 2004;190:478-85.

18. Lal S, Lacroix M, Tofilon P, Fuller GN, Sawaya R, Lang FF. An implantable guide-screw system for brain tumor studies in small animal. J Neurosurg. 2000;92:326-33. 